\title{
Dosimetric comparison of prostate radiotherapy between pelvic node-positive and node-negative patients
}

\author{
S.B. Zincircioglu*, M.H. Dogan, M.A. Kaya, F. Teke \\ Department of Radiation Oncology, Dicle University Faculty of Medicine, Diyarbakir, Turkey
}

\begin{abstract}
- Original article

*Corresponding author:

Seyit B. Zincircioglu, M.D.,

E-mail: sbzoglu@yahoo.com

Revised: December 2020

Accepted: January 2021

Int. J. Radiat. Res., October 2021;

19(4): 1009-1014

DOI: $10.29242 /$ ijrr.19.4.1009

Background: The importance of dose in prostate radiotherapy is well known, and the dosimetric effects of radiotherapy in node-positive or node-negative patients with prostate cancer have become an important issue. Materials and Methods: Helical tomotherapy (TH) plans of 19 pelvic node-positive [THpn $(+)$ plan] or node-negative [THpn(-) plan] patients with prostate cancer were retrospectively created in our clinic. In these plans, the beam angle was set to cover the planning target volume (PTV) of prostate cancer and minimize the dose to the organs at risk, including the bladder, rectum, femoral head, and bowel. Results: There were no differences in the conformity index, $D_{\max }$, $D_{\text {mean }}$, and homogeneity index of PTV between the THpn (+) and THpn (-) plans $(p>0.05)$. However, V95 in the THpn (+) plan was lower than that in the THpn (-) plan ( $p=0.017)$. Moreover, $D_{\max }, \mathrm{V} 75, \mathrm{~V} 70, \mathrm{~V} 65, \mathrm{~V} 60, \mathrm{~V} 50, \mathrm{~V} 40, \mathrm{~V} 30$, and $\mathrm{V} 20$ for the rectum were not significantly different between the two plans ( $p>0.05)$, whereas $D_{\text {mean }}$ was significantly different $(p=0.025)$. $D_{\max }, V 70$, $\mathrm{V} 65$, and $\mathrm{V} 60$ for the bladder were not significantly different between the two plans ( $p>0.05$ ), whereas $\mathrm{V} 55, \mathrm{~V} 50, \mathrm{~V} 40$, and V30 were significantly different $(p<0.05)$. Finally, $D_{\max }$ and $V 50$ for the femoral head and bowel were significantly different between the two plans $(p<0.05)$. Conclusion: The THpn $(+)]$ and [THpn(-) plans achieved acceptable target dose coverage in prostate radiotherapy.
\end{abstract}

Keywords: Prostate cancer, TomoHelical, irradiation.

\section{INTRODUCTION}

Novel radiotherapeutic techniques achieve a highly improved dose distribution during the management of prostate cancer (1). Previously, the coplanar beam arrangement was considered the gold standard; currently, however, various radiation techniques that can deliver relatively high doses to the prostate are available (2), including image-guided intensity-modulated radiotherapy (IG-IMRT) (3), helical tomotherapy $(\mathrm{TH})$ with multileaf collimators (4), modulated volumetric arc therapy (VMAT), CyberKnife (CK; an advanced robotic system) (5), and salvage radiotherapy (SRT) (6). Recent advances in radiotherapeutic techniques have enabled the delivery of highly conformal and homogeneous doses to the target volume while sparing the organs at risk (OARs) $(7,8)$.

The advantage of IMRT in decreasing acute bowel toxicity during whole-pelvis radiotherapy [WPRT node $(+)$ ] in high-risk patients with prostate cancer has been demonstrated in several recent studies in both primary and postoperative settings $(9,10)$. Postprostatectomy radiotherapy improved the outcomes of patients with positive surgical margins (11) and a subset of patients with pelvic lymphatic involvement (12); however, the 10 -year progression-free survival rate of these patients remained between $56 \%$ and $61 \%(13,14)$. Diverse maximum safe doses to the rectum and bladder have been recommended, with the doses at $65 \%$ of the rectal and bladder volumes, 
or below $70 \mathrm{~Gy}$, being the most preferred ones $(15,16)$. Meanwhile, the doses of $\mathrm{V} 50<2 \%$ and Dmax $<50$ Gy have been recommended for the femoral head (17).

In the present study, we aimed to decrease the OAR volume using two TH plans (pelvic node positive or node negative) and compared the developed plans with those of patients with prostate cancer in whom the planning target volume (PTV) coverage had been achieved. Such planning can ensure acceptable toxicity to the OARs. The novelty of these plans is that they minimize radiation exposure of the OARs during prostate radiotherapy.

\section{MATERIALS AND METHODS}

\section{Patients}

In the present planning study, we included 11 pelvic node-positive patients and 8 pelvic node-negative patients with primary prostate cancer, who had undergone prostate-conserving therapy. The median patient age was 48 (24-80) years, and all patients underwent radiotherapy according to the TH plans between March 2016 and August 2017 at the Department of Radiation Oncology of our university hospital. All procedures were approved by the Dicle University Medical Faculty Ethics Committee for Noninterventional Studies (\#06.06.2018/197). The TH plans for the included patients were retrospectively created after receiving their informed consent. The eligibility criterion was the presence of histopathologically proven early stage or pelvic node-positive disease. We compared the pelvic node-positive [THpn $(+)]$ and node-negative $[\operatorname{THpn}(-)]$ plans for prostate-conserving radiotherapy.

\section{Simulation, contouring, planning, and plan assessment}

Computed tomography (CT) images (Toshiba) were obtained for each patient and reconstructed at a slice interval of $3 \mathrm{~mm}$. In the supine position, the patients were screened with a fix-knee (Civco Inc., Orange City, Iowa, USA) immobilization tool. At 30 minutes before CT, the patients were requested to evacuate the 1010 bladder and then drink $0.5 \mathrm{~L}$ of water. Pharmacological and mechanical preparations or endorectal balloon (e.g., enema) were not used. The volume contours and CT images were input in a TH system (Accuray Inc., Sunnyvale, CA, USA) to create the treatment plans. The $\mathrm{TH}$ plans were created to cover the PTV and minimize the dose to the OARs. The OARs included the bladder, rectum, femoral head, and bowel in each patient, and the prostate was included in the irradiation volume. The pitch, field width, and modulator factor of the TH plans were $0.287,2.5 \mathrm{~cm}$, and $3.0 \quad(0.5-4.0)$, respectively.

The dose required to cover the PTV was prescribed as 80 Gy across 40 fractions of $2.0 \mathrm{~Gy}$ per day. As a dose restriction for the PTV, D95 was defined as the minimum dose delivered to $95 \%$ of the PTV, and D95 was $\geq 95 \%$ of the prescribed dose. V95 (76 Gy) was defined as the percentage of the PTV receiving at least $95 \%$ of the prescribed dose, and V95\% was $\geq 95 \%$ of the PTV. Conformity index (CI) was used to evaluate the target dose conformity, and homogeneity index (HI) was used to analyze the uniformity of dose distribution in the target volume. The dosimetric effects on the target and OARs and the treatment time for each $\mathrm{TH}$ plan were assessed by a radiation oncologist.

\section{Statistical analysis}

Data were analyzed using SPSS 16.0 (SPSS, Chicago, IL, USA). All data are presented as mean and/or median and standard deviation. Differences in the dosimetric end-points between the THpn (+) and THpn(-) plans were analyzed using the Wilcoxon signed-rank test. Differences were considered significant at $\mathrm{p}<0.05$.

\section{RESULTS}

We analyzed the differences in dosimetric values between the THpn (+) and THpn(-) plans. Table 1 summarizes the dose parameters of PTV in the two TH plans and the results of dosimetric comparison of these $\mathrm{TH}$ plans in patients with prostate cancer. Figure 1 present the dose Int. J. Radiat. Res., Vol. 19 No. 4, October 2021 
distribution in the THpn (+) and THpn (-) plans, respectively. In the present study, the CI values in the THpn (+) and THpn (-) plans were 0.93 and 0.96 , respectively ( $p>0.05)$. Similarly, the HI values did not significantly differ between the THpn (+) (0.21) and THpn (-) plans (0.23) $(p>0.05)$. Both TH plans achieved clinically acceptable target dose coverage for prostate radiotherapy in this study. However, the $D_{\max }$ of
PTV ( $\mathrm{p}=0.674)$ and mean V95 (the volume receiving $74.1 \mathrm{~Gy})(\mathrm{p}=0.017)$ were significantly different between the two plans.

Among the OARs, $\mathrm{D}_{\text {mean, }} \mathrm{V75}, \mathrm{V} 40, \mathrm{~V} 30$, and V20 for the rectum; $\mathrm{D}_{\text {mean, }} \mathrm{V} 60, \mathrm{~V} 55, \mathrm{~V} 50, \mathrm{~V} 40$, and V30 for the bladder; $D_{\max }$ and V50 for the femoral head; and $D_{\max }$ and V50 for the bowel were significantly lower in the THpn $(-)$ plan than in the THpn $(+)$ plan $(\mathrm{p}<0.05)$.

\begin{tabular}{|c|c|c|c|c|c|}
\hline \multirow[t]{2}{*}{ Parameter } & \multicolumn{2}{|c|}{ Pelvic Node (+) } & \multicolumn{2}{|c|}{ Pelvic Node (-) } & \multirow[t]{2}{*}{ P value } \\
\hline & Median & Range & Median & Range & \\
\hline \multicolumn{6}{|l|}{ PTV } \\
\hline Dmax & 83.25 & 75.84-88.16 & 81.46 & $78.70-86.81$ & 0.674 \\
\hline Dmean & 79.1 & 71.86-86.1 & 78.5 & $76.38-82.82$ & 0.779 \\
\hline V95\% & 98.25 & $97.4-99.8$ & 99.71 & 98.1-99.98 & 0.017 \\
\hline \multicolumn{6}{|l|}{ Rectum } \\
\hline Dmax & 80.3 & 74.47-88.16 & 79.9 & $76.4-86.8$ & 0.327 \\
\hline Dmean & 42.22 & $36.76-50.24$ & 38.32 & 21.3-39.39 & 0.025 \\
\hline V75 & 3.74 & 0-19.74 & 5.85 & $0.2-11.57$ & 0.05 \\
\hline V70 & 8.48 & $1.62-28.43$ & 9.83 & $2.6-18.86$ & 0.093 \\
\hline V65 & 13.37 & 5.45-34.6 & 14.17 & $6.41-25.69$ & 0.123 \\
\hline V60 & 24.76 & 8.75-40.2 & 19.25 & 10.11-31.43 & 0.575 \\
\hline V50 & 33.13 & $16.12-49.84$ & 28.95 & $17.10-39.9$ & 0.123 \\
\hline V40 & 57.81 & $40.40-66.8$ & 40.25 & $21.6-46.6$ & 0.012 \\
\hline V30 & 71.19 & $57.17-92.2$ & 53.4 & $25.9-62.6$ & 0.012 \\
\hline V20 & 83.8 & 79.4-97.7 & 75.7 & $31.4-81.9$ & 0.012 \\
\hline \multicolumn{6}{|l|}{ Bladder } \\
\hline Dmax & 82.5 & $75.84-86.73$ & 80.85 & 78.4-85.99 & 0.779 \\
\hline Dmean & 45.66 & $31.17-50.65$ & 30.63 & $17.8-40.1$ & 0.012 \\
\hline V70 & 14.1 & $7.02-24.32$ & 9.32 & $5.32-16.2$ & 0.161 \\
\hline V65 & 18.51 & $11.32-33.40$ & 13.1 & $7.29-19.40$ & 0.263 \\
\hline V60 & 24.63 & $16.03-42.1$ & 16.95 & $8.99-23.3$ & 0.036 \\
\hline V55 & 33.3 & $20.1-48.3$ & 20.15 & $11.1-27.8$ & 0.017 \\
\hline V50 & 40.75 & $28.88-53.2$ & 23.5 & $13.1-34.2$ & 0.012 \\
\hline V40 & 57.7 & $31.14-74.6$ & 30.65 & $17.6-45.7$ & 0.012 \\
\hline V30 & 72.5 & $41.7-86.5$ & 39.9 & $22.9-59.6$ & 0.012 \\
\hline \multicolumn{6}{|c|}{ Femur Heads } \\
\hline Dmax & 54.1 & $36-60.5$ & 33.25 & $20.42-40.72$ & 0.012 \\
\hline V50 & 0.55 & $0-3.49$ & 0 & $0-0$ & 0.028 \\
\hline \multicolumn{6}{|l|}{ Bowel } \\
\hline Dmax & 50.2 & 25.7-62.34 & 4.15 & 2.6-8.1 & 0.012 \\
\hline V50 & 0 & $0-6.54$ & 0 & $0-0$ & 0.31 \\
\hline \multicolumn{6}{|l|}{ PTV } \\
\hline $\mathrm{HI}$ & 0.1 & $0.07-0,16$ & 0.12 & $0.08-0.29$ & 0.21 \\
\hline $\mathrm{Cl}$ & 0.95 & $0.87-0.97$ & 0.94 & $0.88-0.96$ & 0.077 \\
\hline
\end{tabular}

$\mathrm{Vx}$, volume (\%) receiving $\mathrm{x}$ dose (Gy) or higher; Dmax, maximum dose; Dmean, mean dose. 


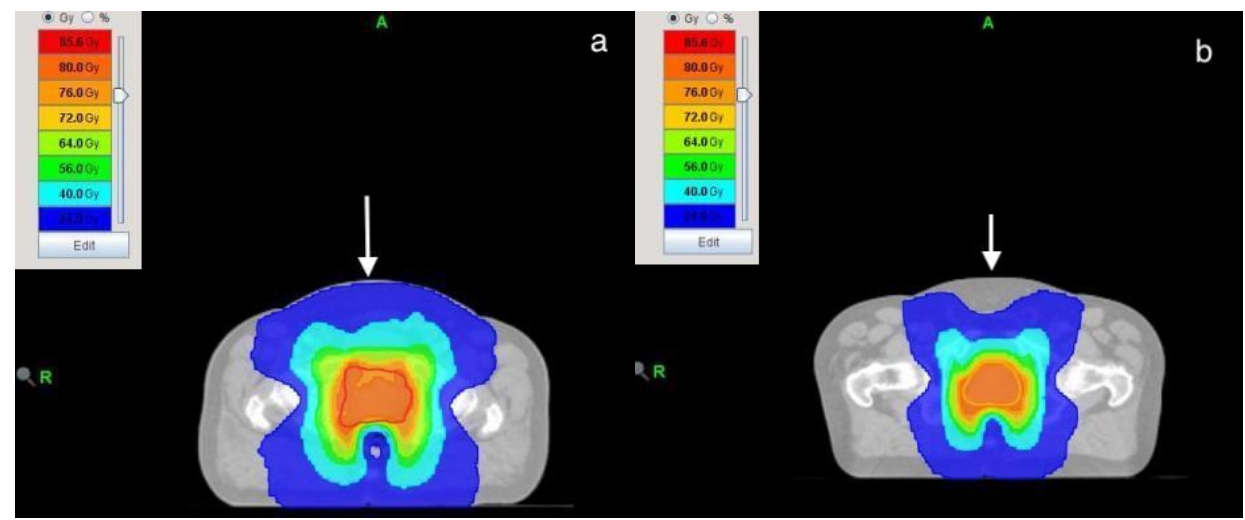

Figure 1. Dose distributions of PTV at prostate (arrow-head) for (a) THpn (+) patients and (b) THpn (-) patients. Different color regions in plans demonstrating exposed radiation doses.

\section{DISCUSSION}

Modern radiotherapeutic techniques aim to provide a more homogenous dose that is compatible to the target volume and, at the same time, spares the OARs (18). VMAT has been considered a reliable option to protect the OARs from radiation during prostate radiotherapy. Thanks to the modern tools of radiation delivery, prostate radiotherapy can be administered both effectively and safely. IMRT, VMAT, CK, and TH are commonly selected for the management of low-risk prostate tumors. Comparisons and calculations of dose distribution among different radiotherapeutic techniques have been reported in the literature (19); however, integral dose for the radiotherapy of localized prostate cancer remains controversial (20). Setup correction strategies determine the PTV margins, and the PTV depends on the setup correction. Due to the misalignment between the prostate and pelvic lymph nodes and the broad margins around the pelvic lymph node, the prostate bed constitutes the smallest part of the prostate PTV. This forms a large intersection zone between the pelvic node-positive part of the PTV and the bladder, rectum, and femoral head. According to a previous study, no correction strategy is optimal, and a comprehensive evaluation of dosimetric effects is imperative (21). Considering that different doses are delivered to the prostate and pelvic lymph node, it is not easy to translate the differences in the intersection zone to their effects on doses delivered to the OARs. In a previous study including pelvic node-positive or node-negative patients, V95 was $95 \%$ and $D_{\max }$ was $<107 \%$ of the PTV (22). In the present study, V95 was $98.25 \%$ in the THpn(+) plan and $98.1 \%$ in the THpn(-) plan, while $D_{\max }$ was 83.25 Gy in the THpn(+) plan and 81.46 Gy in the THpn(-) plan. In a previous study, the $\mathrm{CI}$ of the prostate PTV was $0.98{ }^{(22)}$. In the present study, the CI was 0.93 in the THpn (+) plan and 0.96 in the THpn (-) plan $(p>0.05)$. Similarly, the HI value did not significantly differ between the THpn (+) (0.21) and THpn(-) plans (0.23) ( $p>0.05)$.

$\mathrm{TH}$ decreases acute gastrointestinal (GI) toxicity but increases acute genitourinal (GU) toxicity (23). In a previous study, the rate and prevalence of GI toxicity improved with improved dose compatibility and tumor targeting (24). Meanwhile, acute GU toxicity was not significantly reduced with these so-called improvements (25). IMRT, VMAT, and RapidARC combined with arc-modulated cone beam therapy and TH may achieve the desirable dose distribution while effectively sparing the OARs, specifically the bowel (26). During the pre-IMRT period, most part of the pelvic bowel is inevitably exposed to the prescribed radiation dose; consequently, acute UGI toxicity remains a major concern related to this treatment, particularly in light of the relatively weak evidence of the clinical benefits of WPRT (27). The recommended clinical dose limits for the bowel are a $D_{\max }$ of $56 \mathrm{~Gy}$ and V50 of $15 \%$. In the present study, the $\mathrm{D}_{\max }$ was $50.2 \mathrm{~Gy}$ in the THpn $(+)$ plan and 4.15 Gy in the THpn (-) plan, while V50 was $0 \%$ in both plans $(\mathrm{p}<0.05)$.

Int. J. Radiat. Res., Vol. 19 No. 4, October 2021 
Advances in external beam radiotherapeutic techniques have enabled the delivery of the desired dose while reducing toxicity in patients with prostate cancer $(28,29)$. A previous study showed that clinician differences in goal setting did not change acute toxicity, often due to the negligible distinction between the bladder-prostate and rectal-prostate interfaces (30). If the bladder dose induces GU toxicity, the difference in prostate volume is unlikely to be prone to consequences. However, if the actual prostate dose itself induces GU toxicity, the differences in target volume may lead to changes in toxicity. As expected, the volumes for both groups are typically larger than those in ultrasound-based studies (31). The recommended maximum safe dose to the bladder and rectum is $>65 \%$ of the respective volume, or $<70 \mathrm{~Gy}$ (32). In the present study, V70 was $14.1 \%$ in the THpn $(+)$ plan and $9.32 \%$ in the THpn(-) plan $(\mathrm{p}>0.05)$.

A previous study sought to establish an optimized TH plan for localized dose-escalated prostate radiotherapy (33) based on the recommended dose limits of $\mathrm{V} 65<15 \%$ and V70 $<1 \%$ for the rectum $(34,35)$. In our study, V70 and V65 were respectively $8.48 \%$ and $13.37 \%$ in the THpn (+) plan and respectively $9.83 \%$ and $14.17 \%$ in the THpn (-) plan ( $p>0.05)$. The dose limits are $\mathrm{D}_{\max }<55 \mathrm{~Gy}$ and $\mathrm{V} 50<2 \%$ for the femoral head. In this study, $D_{\max }$ and V50 were respectively 50.2 Gy and $0 \%$ in the THpn (+) plan and respectively 4.15 Gy and $0 \%$ in the THpn $(-)$ plan $(\mathrm{p}<0.05)$.

Overall, we demonstrated that modern radiotherapeutic techniques indeed achieve desirable outcomes in terms of minimizing the radiation dose delivered to the OARs in pelvic node-negative patients with prostate cancer. Further comprehensive studies are warranted to elucidate the effects of node positivity or negativity in patients undergoing prostate radiotherapy.

\section{CONCLUSION}

The dosimetric values in both THpn(+) and THpn(-) plans were lower than the Int. J. Radiat. Res., Vol. 19 No. 4, October 2021 recommended limits. Based on all parameters, the THpn(-) plan may be superior to the THpn(+) plan, as it minimizes the radiation dose to the rectum, bladder, bowel, and femoral head while achieving adequate PTV coverage, with fewer hot-spots.

\section{Funding}

The author(s) received no financial support for the research, authorship, and/or publication of this article.

\section{Conflicts of interest: Declared none.}

\section{REFERENCES}

1. Khoo VS (2005) Radiotherapeutic techniques for prostate cancer, dose escalation and brachytherapy. Clin Oncol, 17 (7): 560-571.

2. Hermesse J, Biver S, Jansen N, Lenaerts E, Nickers P (2010) Dosimetric comparison of high-dose-rate brachytherapy and intensity-modulated radiotherapy as a boost to the prostate. Int J Radiat Oncol Biol Phys, 76(1): 269-276.

3. Jensen L, Yuh B, Wong JYC, Schultheiss T, Cheng J, Ruel N, Twardowski P, Sampath S (2017) Outcomes and toxicity of 313 prostate cancer patients receiving helical tomotherapy after radical prostatectomy. Adv Radiat Oncol, 2(4): 597-607.

4. Rodriques G, Yartsev S, Chen J, Wong E, Souza DD, Lock M, Bauman G, Grigorov G, Kron T (2006) A comparison of prostate IMRT and helical tomotherapy class solutions. Radiother Oncol, 80(3): 374-377.

5. Slosarek K, Osewski W, Grazadziel A, Radwan M, _Dolla T, Szlag M, Fudzinska MS (2014) Integral dose: Comparison between four techniques for prostate radiotherapy. Rep Pract Oncol Radiother, 20(2): 99-103.

6. Lee CG, Lee J, Kim S, You SH (2018) The possibility of hormone- mediated PSA derangement in prostate cancer treatment. Int J Radiat Res, 16(2): 243-250.

7. Michalecki L, Gabrys D, Kulik R, Wydymanski J, Trela K (2011) Radiotherapy induced hip joint avascular necrosisTwo cases report. Rep Pract Oncol Radiother, 16(5): 198201.

8. Piotrowski T, Martenka P, de Patoul N, Jodda A, Coevoet M, Malicki J, Vynckier S (2009) The new two component conformity index formula (TCCl) and dose-volume comparisons of the pituitary gland and tonsil cancer IMRT plans using a linear accelarator and helical tomotherapy. Rep Pract Oncol Radiother, 14(4): 133-145.

9. Arcangeli S, Saracino B, Petrongari MG, Gomellini S, Marzi S, Landoni V, et al. (2007) Analysis of toxicity in patients with high risk prostate cancer treated with intensitymodulated pelvic radiation therapy and simultaneous inte- 


\section{Zincircioglu et al. / Node positivity or negativity in prostate RT}

grated dose escalation to prostate area. Radiother Oncol, 84(2): 148-55.

10. Muren LP, Wasbo E, Helle SI, Hysing LB, Karlsdottir A, Odland OH, Valen H, Ekerold R, Johannessen DC (2008) Intensity-modulated radiotherapy of pelvic lymph nodes in locally advenced prostate cancer: planning procedures and early experiences. Int J Radiat Oncol Biol Phys, 71(4): 1034-41.

11. Thompson IM, Tangen CM, Paredelo J, Lucia MS, Miller G, Troyer D, et al. (2009) Adjuvant radiotherapy for pathological T3NOMO prostate cancer significantly reduces risk of metastases and improves survival: long- term followup of a randomized clinical trial. J Urol, 181(3): 956-62.

12. Abdollah F, Karnes RJ, Suardi N, Cozzarini C, Gandaglia G, Fossati N, et al. (2014) Impact of adjuvant radiotherapy on survival of patients with node-positive prostate cancer. $J$ Clin Oncol, 32(35): 3939-47.

13. Bolla M, Van Poppel H, Tombal B, Vekemans K, Da Pozzo L, de Reijke TM, et al. (2012) Postoperative radiotherapy after radical prostatectomy for high-risk prostate cancer: long-term results of a randomised controlled trial (EORTC trial 22911). Lancet, 380(9858): 2018-27.

14. Wiegel $T$, Bartkowiak $D$, Bottke $D$, Bronner $C$, Steiner $U$, Siegmann A, et al. (2014) Adjuvant radiotherapy versus wait-and-see after radical prostatectomy: 10-year followup of the ARO 96-02/AUO AP 09/95 trial. Eur Urol, 66(2): 243-50.

15. Peeters ST, Heemsbergen WD, Van Putten WL, Slot A, Tabak H, Mens JW, Lebesque JV, Koper PCM (2005) Acute and late complications after radiotherapy for prostate cancer: results of a multicenter randomised trial comparing 68 Gy to 78 Gy. Int J Radiat Oncol Biol Phys, 61(4): 1019-34.

16. Taussky D, Schneider U, Rousson V, Pescia R (2003) Patient -reported toxicity to dose-volume histograms of the rectum in radiotherapy of the prostate. Am J Clin Oncol, 26 (5): e144-49.

17. Longobardi B, Berardi G, Fiorino C, Alongi F, Cozzarini C, Deli A, La Macchia M, Perna L, Di Muzio NG, Calandrino R (2011) Anatomical and clinical predictors of acute bowel toxicity in whole pelvis irradiation for prostate cancer with Tomotherapy. Radiother Oncol, 101(3): 460-4.

18. Bindhu J, Supe S, Pawar Y (2009) Intensity modulated radiotherapy (IMRT) the white, black, and grey: a clinical perspective. Rep Pract Oncol Radiother, 14(3): 95-103.

19. Hermesse J, Biver S, Jansen N, Lenaerts E, Nickers P (2010) Dosimetric comparison of high-dose-rate brachytherapy and intensity-modulation radiation therapy as a boost to the prostate. Int J Radiat Oncol Biol Phys, 76(1): 269-76.

20. Hermanto U, Frija EK, Lii MJ, Chang EL, Mahajan A, Woo SY (2007) Intensity modulated radiotherapy and conventional three-dimensional conformal radiotherapy for high-grade gliomas: does IMRT increase the integral dose to normal brain? Int J Radiat Oncol Biol Phys, 67(4): 1135-44.

21. Kershaw L, van Zadelhoff L, Heemsbergen W, Pos F, van Herk M (2018) Image guided radiation therapy strategies for pelvic lymph node irradiation in high-risk prostate cancer: motion and margins. Int J Radiat Oncol Biol Phys, 100(1): 68-77.

22. Van Nunen A, van der Toorn PPG, Budiharto TCG, Schuring
D (2018) Optimal image guided radiation therapy strategy for organs at risk sparing in radiotherapy of the prostate including pelvic lymph nodes. Radiother Oncol, 127(1): 6873.

23. Keiler L, Dobbins D, Kulasekere R, Einstein D (2007) Tomotherapy for prostate adenocarcinoma: a report on acute toxicity. Radiother Oncol, 84(2): 171-6.

24. Jani AB, Gratzle J, Muresan E, Farrey K, Martel MK (2005) Analysis of acute toxicity with use of transabdominal ultrasonography for prostate positioning during intensity- modulated radiotherapy. Urology, 63(3): 504-8.

25. Zelefsky MJ, Fuks Z, Hunt M, Yamada Y, Marion C, Ling CC, Amols H, Venkatraman ES, Leibel SA (2002) High-dose intensity modulated radiation therapy for prostate cancer: early toxicity and biochemical outcome in 772 patients. Int $J$ Radiat Oncol Biol Phys, 53(5): 1111-6.

26. Cozzarini C, Fiorino C, Di Muzino N, Alongi F, Broggi $S$, Cattaneo M, Montorsi F, Rigatti P, Calandrino R, Fazio F (2007) Significant reduction of acute toxicity following pelvic irradiation with helical tomotherapy in patients with localized prostate cancer. Radiother Oncol, 84(2): 164-70.

27. Spiotto MT, Hancock SL, King CR (2007) Radiotherapy after prostatectomy: improved biochemical relapse-free survival with whole pelvic compared with prostate bed only for high- risk patients. Int J Radiat Oncol Biol Phys, 69 (1): 54-61.

28. Karlsdottir A, Johannessen DC, Muren LP, Wentzel LT, Dahl O (2004) Acute morbidity related to treatment volume during 3D-conformal radiation therapy for prostate cancer. Radiother Oncol, 71(1): 43-53.

29. Hanks GE, Hanlon AL, Ebstein B, Horwitz EM (2002) Dose response in prostate cancer with 8-12 years' follow-up. Int $J$ Radiat Oncol Biol Phys, 54(2): 427-35.

30. Livsey JE, Wylie JP, Swindell R, Khoo VS, Cowan RA, Longue JP (2004) Do differences in target volume definition in prostate cancer lead to clinically relevant differences in normal tissue toxicity? Int J Radiat Oncol Biol Phys, 60(4): 1076-81.

31. Hoffelt SC, Marshall LM, Garzotto M, Hung A, Holland J, Beer TM (2003) A comparison of CT scan to transrectal ultrasound-measured prostate volume in untreated prostate cancer. Int J Radiat Oncol Biol Phys, 57(1): 29-32.

32. Teh BS, Mai WY, Uhl BM, Augspurger ME, Grant 3rd WH, $\mathrm{Lu} \mathrm{HH}$, et al. (2001) Intensity-modulated radiation therapy (IMRT) for prostate cancer with the use of a rectal ballon for prostate immobilization: acute toxicity and dosevolume analysis. Int J Radiat Oncol Biol Phys, 49(3): 70512.

33. Grigorov G, Kron T, Wong E, Chen J, Solazzo J, Rodrigues G (2003) Optimazition of helical tomotherapy treatment plans for prostate cancer. Phys Med Biol, 48(13): 1933-43.

34. Fiorino C, Alongi F, Broggi S, Cattaneo GM, Cozzarini C, Di Muzio N, et al. (2008) Physics aspects of prostate tomotherapy: planning optimization and image-guidances issues. Acta Oncol, 47(7): 1309-16.

35. Alongi F, Fiorino C, Cazzorini C (2009) IMRT significantly reduces acute toxicity of whole-pelvis irradiations in patients treated with post-operative adjuvant or salvage radiotherapy after radical prostatectomy. Radiother Oncol, 93(2): 207-12.

Int. J. Radiat. Res., Vol. 19 No. 4, October 2021 